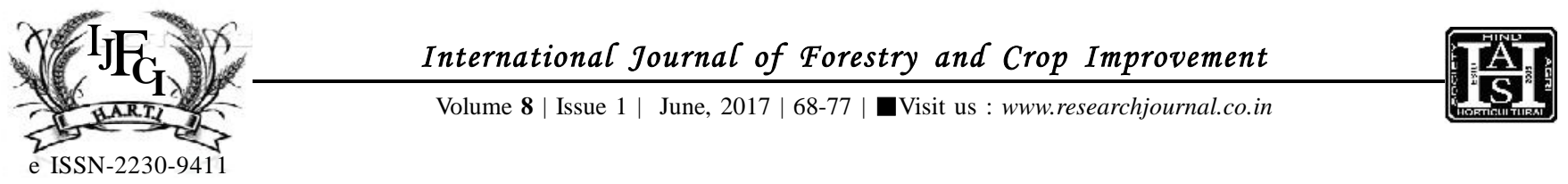

A REVIEW

\title{
Indigenous knowledge in traditional agroforestry systems of Kashmir valley: Current challenges and future opportunities
}

\author{
M.A. ISLAM, K.N. QAISAR AND G.M. BHAT
}

\begin{abstract}
The traditional agroforestry systems have gained wider attention in the international agreements and among academicians and policy makers for their multifunctional role and dynamics of ecosystem services. The multifunctional traditional agroforestry systems support substantial ecosystem services and livelihoods to the rural communities in Kashmir. They are considered to be adaptive to the climate change situations and serve as efficient means to carbon sinks. Due to the remarkable significance of traditional agroforestry systems in the valley ecosystem, environment and livelihood, the systems have been considered as a promising land use pattern in the valley. With climate change rapidly impacting both ecosystems and services in the valley, the sustainability of dynamic traditional agroforestry systems is now facing new challenges and vulnerabilities. Indigenous knowledge on traditional agroforestry is an integral part of the culture and history of the local communities which offer opportunities for sustainable management of resources and support socio-ecological and socio-economic benefits. The indigenous knowledge on agroforestry needs to be further strengthened through research and development to achieve the goals of sustainable development.
\end{abstract}

KEY WORDS : Indigenous knowledge, Traditional agroforestry, Ethno-medico-botany

How TO CITE THIS ARTICLE : Islam, M.A., Qaisar, K.N. and Bhat, G.M. (2017). Indigenous knowledge in traditional agroforestry systems of Kashmir valley: Current challenges and future opportunities. Internat. J. Forestry \& Crop Improv., 8 (1) : 68-77, DOI: 10.15740/HAS/ IJFCI/8.1/68-77.

ARTICLE ChroniCAL : Received : 21.03.2017; Accepted : 25.05.2017

\section{MEMBERS OF RESEARCH FORUM}

Address of the Correspondence : M.A. ISLAM, Faculty of Forestry, Sher-e-Kashmir University of Agricultural Sciences and Technology of Kashmir, Benhama, GANDERBAL (J\&K) INDIA Email: ajaztata@gmail.com

Address of the Coopted Authors : K.N. QAISAR AND G.M. BHAT, Faculty of Forestry, Sher-e-Kashmir University of Agricultural Sciences and Technology of Kashmir, Benhama, GANDERBAL (J\&K) INDIA 